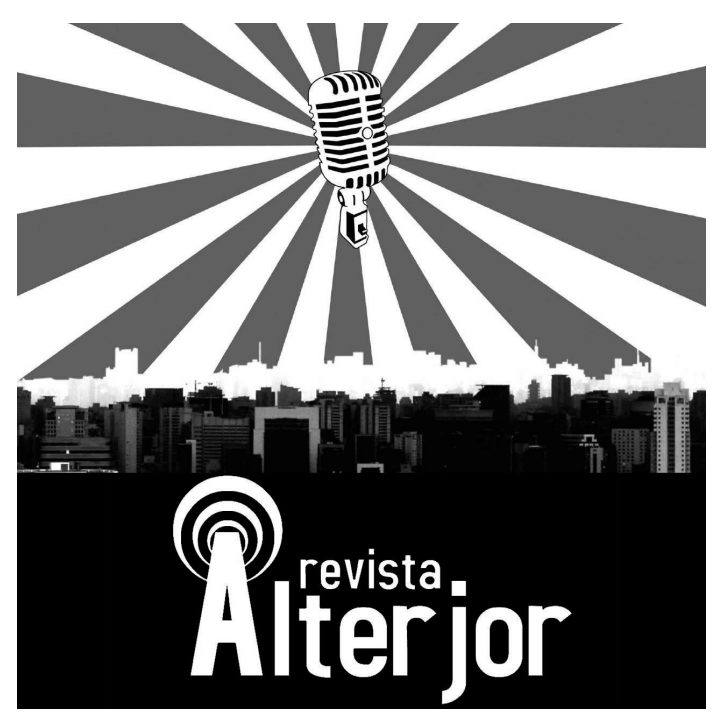

\title{
RESENHA
}

\section{A LÓGICA DA MÍDIA BRASILEIRA E OS DESAFIOS PARA DEMOCRATIZAR A COMUNICAÇÃO}

\section{Carlos Henrique Demarchi ${ }^{1}$}

RESUMO: O debate sobre a atuação da mídia no Brasil, em especial a televisão aberta, é uma das abordagens centrais de "A mídia descontrolada: episódios da luta contra o pensamento único", livro mais recente do professor aposentado da ECA/USP, Laurindo Lalo Leal Filho. Resultado das reflexões do autor em artigos publicados na Revista do Brasil entre 2010 e 2018, a publicação levanta a crítica sobre temas como o posicionamento político adotado pelo jornalismo, a criminalização dos movimentos sociais e a ausência de regulação democrática do setor de comunicação. Também traz análises de como a hegemonia do sistema privado de mídia sobre as esferas cultural, social e política impõe obstáculos à luta pela democratização da comunicação e, por conseguinte, à veiculação de ideias alternativas.

PALAVRAS-CHAVE: Democratização da comunicação. Regulação democrática. Contrahegemonia. Radiodifusão. Cidadania..

ABSTRACT: he debate about media in Brazil, especially broadcasting television, is one of the centres discussions of the recently published book A mídia descontrolada: episódios da luta contra o pensamento único, written by São Paulo University retired professor Laurindo Leal Filho. Resulted of a series of author's articles that were published in the magazine Revista do Brasil between 2010 and 2018 , the book debate topics such as the political position adopted by journalism, the criminalization of social movements and the lack of democratic regulation in media sector in Brazil. It also provides analyzes of how the private media power over the cultural, social and political spheres can impose obstacles to the struggle for democratization of media communication and, consequently, to the spreading of alternative ideas.

KEYWORDS: Democratization of media communication. Regulation. Counter hegemony. Broadcasting. Citizenship.

\footnotetext{
I Doutor em Comunicação pela Universidade Estadual Paulista (UNESP), campus de Bauru. Membro do grupo de pesquisa Estado e Governo. Professor do Centro Universitário Católico Salesiano Auxilium (Unisalesiano), campus de Araçatuba. E-mail: carlos.demarchi@unesp.br
}

Revista ALTERJOR

Grupo de Estudos Alterjor: Jornalismo Popular e Alternativo (ECA-USP)

Ano 10 Volume Ol Edição $21 \quad$ Janeiro-Julho de 2020

Avenida Professor Lúcio Martins Rodrig̉ues, 443, Cidade Universitária, São Paulo, CEP: 05508-020 
“A mídia descontrolada: episódios da luta contra o pensamento único" é o nome do livro mais recente de Laurindo Lalo Leal Filho, professor aposentado da Escola de Comunicações e Artes da Universidade de São Paulo (ECA-USP). A obra foi lançada e publicada em 2018 pelo Centro de Estudos da Mídia Alternativa Barão de Itararé.

O livro é composto de um conjunto de artigos do autor publicados na Revista do Brasil no período 2010-2018. Com linguagem simples e direta, a publicação fornece elementos para o leitor compreender as principais características do sistema midiático brasileiro.

A mídia televisiva está no eixo central dos textos. Por se tratar de concessão pública, o autor sinaliza as responsabilidades das emissoras concessionárias, que devem condizer com as regras de qualidade inerentes à prestação de serviços públicos, como o transporte público e a coleta de lixo. Neste contexto, canais de avaliação ao alcance do público e regras disciplinadas por um órgão regulador tornam-se essenciais.

Ao descrever passagens nas quais os meios de comunicação hegemônicos adotaram o pensamento único como linha de atuação, em especial no jornalismo da televisão aberta, o autor expõe a parcialidade da mídia em suas narrativas, que por sua vez poderiam ser mais equilibradas e diversificadas. Constam observações desta ordem em artigos sobre a Copa do Mundo, as eleições de 2014 e as Olimpíadas de 2016.

Laurindo Lalo Leal Filho defende a tese da democratização da comunicação como condição para ampliar a participação de vozes contra-hegemônicas no ecossistema midiático. Em consequência da democratização, haveria incremento de visões alternativas sobre os mais variados temas na esfera pública, algo pouco comum na grade de programação dos canais de TV.

Seguindo esta linha dos princípios inerentes às emissoras, na seção "Regulação da mídia não é censura", o autor enfatiza como a temática da regulação dos meios de comunicação está na ordem do dia de grandes democracias do mundo sem que isso seja configurado censura, tal como argumentam os concessionários das redes de televisão no Brasil.

Em um dos artigos mais extensos da obra, intitulado "Mais liberdade de expressão, mais democracia", o autor concebe que "[...] a regulação pode e deve ir além dos limites 


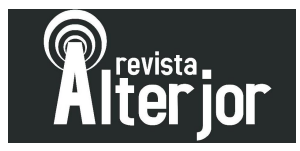

econômicos, estendendo suas regras para garantir o equilíbrio informativo, o respeito à privacidade e a honra das pessoas, os espaços no rádio e na TV aos movimentos sociais, a promoção da cultura nacional, a regionalização da produção artística e cultural e a proteção de crianças e adolescentes diante de programas e programações inadequadas às respectivas faixas etárias" (Leal Filho, 2018:12).

Se observados na totalidade, os assuntos evocados nos textos têm como fio condutor a necessidade histórica de atualizar a legislação brasileira do setor, hoje defasada. Desta forma, Lalo detalha os pontos principais dos cinco artigos do Capítulo da Comunicação Social na Constituição Federal de 1988, esboçando o que seriam diretrizes para assegurar a democratização da área, segundo os princípios constitucionais.

Aspectos como as finalidades educativas, culturais, artísticas e informativas da produção e programação das emissoras de rádio e televisão, a necessidade de regionalização de conteúdos e de equilíbrio entre os sistemas de comunicação privado, público e estatal também aparecem em destaque no livro.

A realidade da comunicação brasileira é comparada com a de vários países que estabeleceram mecanismos de controle democrático dos meios, com ações para proteger os direitos humanos e respeitar as normas previstas no ordenamento jurídico nacional. A estagnação das políticas de comunicação no Brasil, nas quais o empresariado de radiodifusão exerce poder com reduzidos limites, é contraposta a realidades internacionais marcadas pelo enfrentamento à concentração dos meios.

Na América Latina, Lalo menciona avanços nas políticas de comunicação da Argentina que, por meio da Lei de Meios, reorientou o cenário da comunicação daquele país, após anos sob a hegemonia do Grupo Clarín. Nos textos mais recentes do livro, contudo, o autor acompanha as investidas do governo Mauricio Macri contra a legislação argentina, que acabou enfraquecida e sofrendo retrocessos.

Como saídas para combater a preponderância do sistema comercial de radiodifusão e apresentar conteúdos mais comprometidos com as causas sociais para o telespectador, o autor avista a importância da construção de um robusto sistema público de comunicação. 


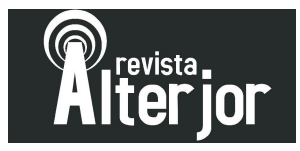

Em diversas passagens da obra, Lalo Leal Filho, que foi ouvidor-geral da Empresa Brasil de Comunicação (EBC), discorre sobre os desafios para se construir outra forma de comunicação em condições de oferecer conteúdos pautados pela cidadania e não pelo mercado.

A defesa destas ideias ocorre principalmente na seção "Valor da comunicação pública”. Já em "Ascensão e queda da comunicação pública”, o autor trabalha com a relevância da comunicação pública no Brasil, que vinha sendo construída com a EBC, mas experimentou problemas recentes, principalmente por conta de ingerências políticas.

O autor reforça a importância da implementação de canais de participação dos cidadãos na mídia, mediante a criação de ouvidorias e de conselhos de comunicação social. Essas instâncias participativas são tomadas como essenciais em qualquer país democrático, nas esferas municipais, estaduais e federal.

Em vários trechos da obra, Lalo Leal Filho refere-se à $1^{\text {a }}$ Conferência Nacional de Comunicação (Confecom), realizada no país em 2009 e que abriu expectativas de avanços nas políticas de um setor marcado pelo não-debate. Quase uma década depois da conferência, observa-se a atualidade das abordagens do autor no tocante às dificuldades para se discutir a comunicação e conseguir avanços.

A preocupação com a permanência de programas policialescos na grade de emissoras de TV aberta é outra inquietação em evidência na publicação. É mister que a mídia respeite os direitos humanos, previstos inclusive em pactos internacionais dos quais o país é signatário.

Também passam pelas reflexões do autor a concentração da mídia no eixo RioSão Paulo, o avanço do conservadorismo e alinhamento político da mídia e a criminalização dos movimentos sociais e populares. A seção "O Brasil não se vê na TV", por exemplo, revela como a cobertura, a técnica, a linha editorial e a linguagem nos canais de televisão muitas vezes não dialogam com o seu público, que é tomado como homogêneo pelos índices de audiência.

Contrapondo-se à influência exercida pela televisão aberta no Brasil, Lalo Leal Filho não deixa de assinalar o papel desempenhado pela internet, blogs e redes sociais, 


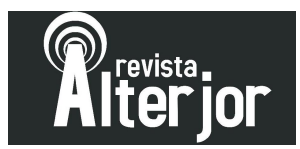

que acabam promovendo rupturas a esse bloqueio midiático, por meio da propagação de ideias alternativas ausentes dos grandes veículos.

Em crescimento no país, o acesso à internet tem potencializado esse espaço para a democratização e o surgimento de visões alternativas, ressalta o autor, que durante dez anos apresentou o VER TV, programa de debate exibido pela TV Brasil e TV Câmara sobre o papel da televisão na sociedade brasileira.

"A mídia descontrolada" é leitura recomendada a todos os interessados na temática da democratização da comunicação e em entender o sistema midiático existente no Brasil. Trata-se de uma obra que desnuda o pensamento único dos meios de comunicação.

Laurindo Lalo Leal Filho é autor de outros livros: "Atrás das Câmeras: relações entre Estado, cultura e televisão"; "A melhor TV do mundo: o modelo britânico de televisão", "A TV sob controle: a resposta da sociedade ao poder da televisão" e "Vozes de Londres: memórias brasileiras da BBC". O autor também já escreveu uma série de artigos sobre cultura e comunicação, com destaque para o tema da televisão, em publicações científicas e de divulgação.

\section{Referência}

LEAL FILHO, Laurindo. A mídia descontrolada: episódios da luta contra o pensamento único. São Paulo: Centro de Estudos da Mídia Alternativa Barão de Itararé, 2018. 